\title{
Türkiye' den Trichodinid Protozooan Trichodina heterodentata ve T. pediculus (Ciliophora: Trichodinidae) İçin Yeni Konak Kaydi ${ }^{\#}$
}

\author{
Saadet Yağmur ÇELİK¹, Jale KORUN ${ }^{*}$ \\ 1 Akdeniz Üniversitesi, Su Ürünleri Fakültesi, Yetistiricilik Bölümü, Ballk Hastalılar Anabilim Dalı, Kampüs, 07058, \\ Antalya, Türkiye \\ *Corresponding author e-mail: jalekorun@akdeniz.edu.tr
}

\#Bu çalsşma Akdeniz. Üniversitesi Bilimsel Araștırma Projeleri Koordinasyon Birimi tarafindan 2013.02.0121.025 nolu proje ile desteklenmis olup, yükesek. lisans tezinin bir kısmundan hazırlanmıștır.

\begin{abstract}
ÖZ
Bu çalışmada, Cichlidae familyasına ait sarı prenses (Labidocbromis caeruleus), mavi prenses (Pseudotropheus socolofi) ve ahli çiklit (Sciaenochromis fryeri) balıkları ile Poecilidae familyasına ait velifera (Poecilia velifera) ve beyaz moli (Poecilia sphenops) balıklarının ektoparazitolojik yönden incelenmesi amaçlanmıştır. Aralık 2013- Kasım 2014 periyodunda ticari bir çiftlikten 600 balık örneği alınmıştır. Deri ve solungaç lamellerinden hazırlanan sürtme preparatların mikroskobik incelemesinde Trichodina sp.(Ehrenberg 1831) siliyatları tespit edilmiştir. Trichodinidler görüldügünde Klein'in kuru gümüş boyama metodu kullanılarak yapışkan disk belirginleştirilmiştir. Sonuçlar Trichodina pediculus' ün radial iğne sayısı ve dentikül mesafesinin T. heterodentata' dan farklı olduğunu göstermiştir. T. pediculus' ün vücut çap1 55-70 (57,6 $\pm 1,03) \mu \mathrm{m}$ ve T. heterodentata' nin vücut çap1 50-60 (54,72 $\pm 0,52) \mu \mathrm{m}$ olarak ölçülmüsstür. T. pediculus' ün yapışkan disk çapı $38-49(44,78 \pm 0,47) \mu \mathrm{m}$ ve $T$. beterodentata nın 34-49 $(44,85 \pm 0,51) \mu \mathrm{m}$ olarak belirlenmiştir. Etkilenen balıklar anormal davranışlar veya klinik bulgu göstermemiştir. Bu çalışmada Trichodina pediculus ve T. heterodentata (Ciliophora: Trichodinidae) için yeni konak kayıtları bildirilmiştir.
\end{abstract}

Anahtar kelimeler: Akvaryum, protozoan, parazit, yeni konak

\section{New Host Records For Trichodinid Protozoans, Trichodina heterodentata and T. pediculus (Ciliophora: Trichodinidae) from Turkey}

\begin{abstract}
In this study, we aimed, certain ornamental fish which the members of Cichlidae including the electric yellow (Labidochromis caeruleus), powder blue cichlid (Pseudotropheus socolofi), electric blue hap (Sciaenochromis fryeri) and the members of Poecilidae including yucaten molly (Poecilia velifera), white molly (Poecilia sphenops) were examined for ectoparasitological. Six hundred fish samples collected from a commercial farm December 2013 through November 2014. Microscopical examination of the smear preparations prepared skins and gill lamellae of them showed Trichodina sp. (Ehrenberg 1831) ciliates. When trichodinids observing, Klein's dry silver method was used to confirm the adhesive disc. Results showed numbers of radial pins and size of denticle span of Trichodina pediculus were different from those of $T$. heterodentata. The body diameter of $T$. pediculus was 55-70 $(57,6 \pm 1,03) \mu \mathrm{m}$ and the body diameter of $T$. heterodentata was 50-60 (54,72 $\pm 0,52) \mu \mathrm{m}$. Width of the adhesive disc diameter was 38-49 $(44,78 \pm 0,47) \mu \mathrm{m}$ for $T$. pediculus and was $34-49(44,85 \pm 0,51) \mu \mathrm{m}$ for T. heterodentata. The affected fish did not show up unusual behavior or external clinical findings. Trichodina pediculus and T. heterodentata (Ciliophora: Trichodinidae) are informed for new hosts at first time in this study.
\end{abstract}

Keywords: aquarium, protozoan, parasite, new host

To cite this article: Celik S.Y. Korun J. Türkiye' den Trichodinid Protozooan Trichodina heterodentata ve T. pediculus (Ciliophora: Trichodinidae) İcin Yeni Konak Kaydr. Kocatepe Vet J. (2018) 11(2): 245-254. 


\section{GİRİ̧̧}

Dünya genelinde akvaryum balığ1 endüstrisi Brezilya, Hindistan, Singapur ve Sri Lanka dahil birçok ülkede evcil hayvan endüstrisinin büyük bir kısmını oluşturmaktadır (Ghosh ve ark., 2003, Ling ve Lim 2005, Mandal ve ark., 2012, Martins ve ark., 2012). Günümüzde akvaryum balığ1 endüstrisi milyonlarca dolarlık bir sektör haline gelmiştir (Thilakaratne ve ark., 2003, Singh ve Sreedharan 2009). Evcil hayvan pazarlarındaki süs balıklarının büyük çoğunluğunun orijini tatlı su yetiştiriciliği oluşturmaktadır (Iqbal ve Haroon 2014). Diskus (Symphysodona equifaciatus), lepistes (Poecilia reticulate), kilıçkuyruk (Xiphophorus helleri), molly (Poecilia sphenops, P. latipinna) ve japon (Carassius auratus) yetiştiriciliği yapılan akvaryum balıkları içerisinde popüler balı türlerdir (Velasco-Santamaría ve Corredor-Santamaría 2011).

Parazitik enfeksiyonlar kültürü yapılan balıklar için en önemli sorunlar arasında yer alır. Uygun olmayan su kalitesi, su sıcaklığındaki dalgalanmalar dahil çevresel parametrelerdeki değişiklikler ile balıklara elleme ve yoğun olarak stoklama, farmasötik tedavi uygulamaları gibi işletme faaliyetleri yoğun kültür şartlarında balıklar üzerine etki ederek, balıklarin homeostatik mekanizmalarına baskı yapar. Bu durum, balıkların ortamda bulunan parazitlere karşı savunmasız kalmalarına yol açar (Thilakaratne ve ark., 2003). Tatlı su balıklarında görülen parazitik türlere protozoan, myxozoan, helmint ve krustasean türleri dahildir. Trichodina sp. dahil protozoan ektoparazitler diğer parazitik türler arasında en tehlikeli gruptur. Trichodinidler tatlı su akvaryum balıklarının deri ve solungaçlarına yerleşerek balıkların büyüme performansları üzerine olumsuz etki yapar (Athanassopoulou ve ark., 2009, Iqbal ve Haroon 2014).

Trichodinidler aboral yüzey üzerindeki kompleks yapıları ve sahip oldukları yapışkan diskleriyle Trichodinidae familyası üyeleri arasında yer alır. Bu disk, parazitin hızlı ve dairesel şekilde hareket etmesine imkan verir. Yoğun kültür koşulları altında trichodinid sayısinın hizla artması sonucu parazitin dairesel hareketleri konak vücut yüzeyinde aşındırıcı lezyonlara neden olabilir. Vücut yüzeyinde meydana gelen lezyonlar sonucu gelişen sekonder bakteriyel enfeksiyonlar balık kayılarını arttırabilir (Iqbal ve Haroon 2014, Valladãa ve ark.,., 2015). Akvaryum balıklarında trichodinid enfeksiyonlar1 Brezilya, Pakistan ve Sri Lanka dahil dünya genelinde bildirilmiştir (Thilakaratne ve ark., 2003, Martins ve ark., 2012, Iqbal ve Hassain 2013). Akvaryum balıklarından bildirilen trichodinid türler arasinda Trichodina nigra, T. acuta,
$T$. reticulate, $T$. luzhones ve $T$. mutabilis gibi trichodinidler yer almaktadır (Valladão ve ark., 2015).

Trichodina pediculus ilk kez 1786' da Cyclidium pediculus olarak tanımlanarak 1838' de tür ismi T. pediculus şeklinde değiştirilmiştir. T. pediculus hidra, balık ve amfibien gibi geniş konak dağılımı gösterir (Gaze ve Wotten 1998). Bu trichodinid parazitin konak seçiciliğinin düşük olmasına karşın konak dağılımı Cypriniformes ve Perciformes olmak üzere iki takım ve Cyprinidae, Cichlidae, Centrarchidae, Odontobutidae ve Nonidae familyaları dahil beş familyayı içerir (Drobiniak ve ark., 2014). Kazubski (1991) T. pediculus Polonya' da japon balığından bildirmiştir. Bashe ve Abdullah (2010) bu türü Irak' ta dikenli y1lan balığ1 (Mastacembelus mastacembelus)'nın derisinde tespit etmiştir. Ülkemizde ise Çapar Dinçer (2016) İç Anadolu Bölgesi' nin farklı göllerindeki siliyat faunasını araştırmış ve Ankara Mogan Gölü' nden $T$. pediculus'u bildirmiştir.

Trichodina heterodentata kozmopolitan bir tür olup ilk kez 1977' de Duncan tarafindan rapor edilmiştir. Dove (2000) T. beterodentata' y1 kiliç kuyruk (X. helleri) ve kırmızı plati (X. maculatus) balıklarından izole ederken, Dove ve O'Donoghue (2005) ise $T$. beterodentata' y1 doğu sivrisinek balığ1 (Gambusia bolbrooki) ve lepistes (P. reticulate)'ten bildirmiştir.

'Türkiye' de yetiştiriciliği yapılan başlıca akvaryum balığ1 türleri arasında lepistes (Poecillia reticulata), melek balığ1 (Pterophylum scalarae), japon (Carassius auratus), diskus (Symphysodon aequifasciatus), ve moli (Poecilia sphenops) gelmektedir. Bu çalışma, Antalya civarında akvaryum balığ1 üretimi yapan ticari bir işletmeden temin edilen farklı süs balığ1 türlerinden Trichodina beterodentata ve $T$. pediculus trichodinidleri için yeni konak kayıtlarını bildirmektedir.

\section{MATERYAL ve METOD}

Çalışma Akdeniz Üniversitesi Hayvan Deneyleri Yerel Etik Kurulu tarafindan 2013.07.03 protokol numarasiyla Etik Kurul onayı alınarak gerçekleştirilmiştir. Çalışma süresince Antalya civarında faaliyet gösteren ticari bir akvaryum balığ1 işletmesinden Cichlidae familyasına dahil sar1 prenses (Labidochromis caeruleus, Fryer 1956), mavi prenses (Pseudotropheus socolofi, Johnson 1974), ahli çiklit (Sciaenochromis fryeri, Konings 1993) ve velifera (Poecilia velifera Regan, 1914) ile Poecilidae familyas1 üyelerinden beyaz moli (P. sphenops, Valenciennes 1846)'nin dahil olduğu toplamda altıyüz balik örneği ile çalışılmıştır. Örnekleme çalışmalarına Aralık 2013 de başlanılıp çalışma, Kasım 2014’e kadar devam etmiştir. Örnekleme zamanlarında 
akvaryumlarda bulunan suyun sicaklığ1, çözünmüş oksijeni ve pH'ı ölçülerek kaydedilmiştir.

Balık örnekleri işletmeden laboratuvara içerisinde havalandırılmış su içeren polietilen torbalar kullanılarak nakledildi. Laboratuvar koşullarında balıkların vücut ağırlıkları ölçülüp kaydedildi. Balıklardaki mevcut parazitleri incelemek için standart parazitolojik yöntemler kullanıldı (Roberts 1989, Lom ve Dykovà 1992). Balıkların deri ve solungaçlarından sürtme preparatlar hazırlanarak mikroskop altında incelendi. Balıkların mide barsak, karaciğer, dalak ve böbreklerinden örnekler alınarak incelendi. Sürtme preparatlarda trichodinid parazitler gözlendiğinde, bu preparatlar havada kurutalarak yapışkan diski ortaya çıkarabilmek için Klein'in kuru gümüş boyama yöntemi ile boyandı (Klein 1958). Tricodinid türlerinin belirlenmesinde, parazitlerin vücut çapları, yapışkan disk çapları, radyal iğneler, diş halka çapları, sınır membranı, bıçak uzunluğu, işı̇n uzunluğu ve dentikül mesafesi ölçümleri mikrometrik oküler kullanılarak yapıldı (Resim 1). Parazit fotoğrafları, mikroskoba tak1lı olan Nikon kamera ile çekildi.

Tüm ölçümlerin aritmetik ortalamaları hesapland1. Prevalans, ortalama yoğunluk ve ortalama bolluk değişimleri için varyans analizi ve Dukan testi uyguland1. Parazitler arasinda ortalama bolluk ve su sicaklığı arasındaki ilişki korelasyon analizi ile test edildi. İstatistiksel olarak anlamlı olan $\mathrm{p} \leq 0.05$ seçildi.

\section{BULGULAR}

On iki ay boyunca her ay işletmeye gidilerek suyun çözünmüş oksijen, pH ve sicaklık değerleri ölçüldü. Elde edilen verilere göre, en yüksek su sicaklık değeri $25,8{ }^{\circ} \mathrm{C}$ ile Haziran, Temmuz ve Ağustos aylarında, en düşük su sicaklık değerinin $23,1{ }^{\circ} \mathrm{C}$ ile Kasım ayında olduğu belirlendi. En yüksek çözünmüş oksijen miktarı 6,9 mg/1 ile Aralık ayında, en düşük çözünmüş oksijen miktarı 4,7 mg/l ile Mayıs, Haziran, Temmuz ve Ağustos aylarında tespit edildi. En yüksek pH değeri 8,40 değeri ile Ocak ayında, en düşük pH değeri ise 7,10 ile Haziran ve Temmuz aylarında kaydedildi.

Çalışma süresince ortalama 1,5-2,5 gram ağırlı̆̆ında ve 3,5-4,5 santimetre uzunluğunda sar1 prenses, mavi prenses, ahli çiklit, velifera ve beyaz moli türleri ile çalışılarak toplam altıyüz balık örneği incelendi. Bu balıklardan \%13,6' sinın iki farklı trichodinid türü ile enfeste olduğu bulundu. Çalışmada T. pediculus' un sarı prensesin (L. caerulus) $\%$ 6,6 sinı, mavi prensesin ( $P$. socolofi) \%8,3 ünü, veliferanin ( $P$. velifera) \%9,1 ini, beyaz molinin $(P$. sphenops) ise \%10,8 ini enfeste ettiği, T. heterodentata' n1n ise ahli çiklitin ( $S$. fryer ) \% $\% 25,8$ ini ve beyaz molinin (P. sphenops) \% \%,5 ini enfeste ettiği tespit edilmiştir. Enfeste balık örneklerinin sadece derilerinden hazırlanan sürüntülerde trichodinid türleri gözlenmiştir. Parazitten etkilenen balıklarda normal olmayan davranışlar ve/veya klinik bulgular tespit edilmemiştir. Altıyüz balık için trichodina türlerinin prevalans1 \%13,7 olup, en yayg1n görülen tür ise $\% 51,2$ ile $T$. pediculus olmuştur. $T$. beterodentata'nin baskinlığ ise $\% 3.3$ olarak bulunmuştur. Çalışmada, tespit edilen T. pediculus ile T. heterodentata'nin (Familya Trichodinidae Claus 1874, Cins Trichodina Ehrenberg 1838) tanımlar1, şekilleri, prevalansları ile ortalama yoğunlukları Tablo 1 de verilmiştir. Balık örneklerinin endoparazit yönünden incelenmesi sonuçlarına göre, balıklarda herhangi bir endoparazit türüne rastlanılmamıştır.

Trichodina pediculus dentüküllerinde orak şeklinde bıçakları, hafif kavisli ve çok uzun 1şınlara sahiptir. Bıçaklar kenarına doğru sivrileşir (Resim1). Vücut

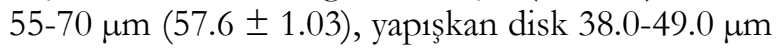
(44.78 \pm 0.47$)$, dentikül halkasının çap1 21.0-35.0 $\mu \mathrm{m}$ (28.92 \pm 0.63), merkezi halka 11.0-20.0 $\mu \mathrm{m}$ (14.61 \pm 0.49$)$ çapındadır. Dentükül halkası 23-24 dentükül içerir ve dentikül başına 9-12 radyal iğne bulunur. Merkezi bölgenin eni 2-3 $\mu \mathrm{m}$, dentikül mesafesi $4 \mu \mathrm{m}$ ' dir. Makronukleus at nalı şeklindedir ve vücudun merkezinde 1şınların son noktasına yerleşmiştir. Mikronukleus küçük çubuk şekillidir ve makronukleusun son ucuna yerleşmiş haldedir. Morfometrik veriler Tablo 2' de verilmiştir. Havada kurutulmuş T. pediculus preparatları gümüş boyama yöntemiyle boyanmış ancak örnek boyayı almamıştır.

Trichodina heterodentata dolgun biçaklara sahiptir. Bu trikodinid parazitin dentikülleri geniş bıçak, güçlü çubuk şekilli olmaları ile karakterize edilir bunlar merkezdeki sivri uçlar ile bağlantılı olan bıçakların apofizi ile sağlanır. Merkezi cisimcikler yoktur, bıçağın antreriör kenarı keskin biçimde aşağı doğru kıvrımlıdır. Bıçaklar y ve $\mathrm{y}^{-1}$ eksenleri arasındaki boşluğu doldurur ve bıçağın tepe kısmı yuvarlaktır $\mathrm{y}^{+1}$ eksenine değer. Bıçak bağıntıları kalındır. Işın uzun sağlam ve y ile $\mathrm{y}+1$ eksenleri arasında konumlanmıştır (Resim2 a ve b). T. heterodentata ya ait morfometrik veriler Tablo 3 de verilmiştir. Morfometrik verilere ilişkin değerlendirmeler Roberts (1989), Lom ve Dykovà (1992) ve Özer ve Öztürk (2015) isimli araştırmaciların çalışmalarından yararlanılarak yapılmıştır. 
Tablo 1. Enfeste balıkların trikodinid parazitlerinin prevalansı ve yerleşim yerleri.

Table 1. The prevalance and localities of trichodinid parasites of the infested fish.

\begin{tabular}{lclccc}
\hline \multicolumn{1}{c}{ Konak } & Örnek Sayıs1 & \multicolumn{1}{c}{ Parazit Türü } & Yerleşim Yeri & Enfeste Balık & Prevalans \\
\hline L. caeruleus & 120 & Trichodina pediculus & Deri & 3 & $\% 2,5$ \\
P. socolofi & 120 & Trichodina pediculus & Deri & 4 & $\% 3,3$ \\
S. fryeri & 120 & Trichodina heterodentata & Deri & 3 & $\% 2,5$ \\
P. velifera & 120 & Trichodina pediculus & Deri & 4 & $\% 3,3$ \\
& 120 & Trichodina pediculus & Deri & 3 & $\% 2,5$ \\
P. sphenops & & Trichodina heterodentata & Deri & 1 & $\% 0,8$ \\
\hline
\end{tabular}

Trichodina pediculus ( $\mathrm{n}=14)$ (Resim1)

Tablo 2. Trichodina pediculus' un morfometrik verileri (parantez içinde aritmetik ortalama ve standart hata $\mu \mathrm{m}$ olarak verilmiştir).

Table 2. Morphometrical data of Trichodina pediculus (with arithmetic mean and standard error in parentheses, all measurements in $\mu \mathrm{m})$.

\begin{tabular}{|c|c|c|c|c|}
\hline Araştırmaci & Bu Çalışma & Kazubski (1991) & Gaze veWootten (1998) & $\begin{array}{c}\text { Bashe ve Abdullah } \\
\text { (2010) }\end{array}$ \\
\hline Konak & $\begin{array}{l}\text { L. caeruleus, } P \text {. socolofi, } \\
\text { P. velifera, } P \text {. sphenops }\end{array}$ & Carassius carassius & Gasterosteus aculeatus & $\begin{array}{l}\text { Mastacembelus } \\
\text { mastacembelus }\end{array}$ \\
\hline Yerleşim & Deri & - & Deri & Deri \\
\hline Yer & Antalya, Türkiye & Kortowo, Polonya & Airthrey Loch, Central Region & $\begin{array}{c}\text { Greater Zab Nehri, } \\
\text { Irak }\end{array}$ \\
\hline Vücut Çap1 & $55-70(57.6 \pm 1.03)$ & - & - & $55-70$ \\
\hline Yapışkan disk çapı & $38-49(44.78 \pm 0.47)$ & $54.96 \pm 4.52$ & $46.0-57.2(50.1 \pm 3.6)$ & $43-66$ \\
\hline $\begin{array}{l}\text { Dentiküler halka } \\
\text { çapı }\end{array}$ & $21-35(28.92 \pm 0.63)$ & $35.70 \pm 2.83$ & $29.3-34.0(32.0 \pm 1.6)$ & $28.3-44.6$ \\
\hline Merkezi halka çapi & $11-20(14.61 \pm 0.49)$ & - & - & $11-24$ \\
\hline Dentikül sayıs1 & $23-24$ & $28-29$ & $26-29(27)$ & $25-30$ \\
\hline Radial iğne/dentikül & $9-12$ & - & $6-8(7.5 \pm 0.8)$ & $9-9.6$ \\
\hline Sinir membran & $3-5(3.42 \pm 0.11)$ & 3.9 & $3.4-5.0(4.4 \pm 0.4)$ & - \\
\hline Bıçak uzunluğu & $5-7(5.76 \pm 0.13)$ & - & $4.9-6.2(5.6 \pm 0.3)$ & - \\
\hline Işın uzunluğu & $7-9(7.19 \pm 0.16)$ & - & $9.2-13.6(11.6 \pm 1.3)$ & - \\
\hline Merkezi bölge eni & $2-3(2.30 \pm 0.07)$ & - & $1.3-2.5(1.9 \pm 0.3)$ & - \\
\hline Dentikül mesafesi & 4 & $19.12 \pm 2.38$ & $16.6-21.8(18.9 \pm 1.6)$ & - \\
\hline
\end{tabular}

Trichodina heterodentata $(\mathrm{n}=4)($ Resim2) 
Tablo 3. Trichodina heterodentata nın morfometrik verileri (parantez içinde aritmetik ortalama ve standart hata, tüm ölçümler $\mu \mathrm{m}$ cinsinden).

Table 3. Morphometrical data of Trichodina heterodentata (with arithmetic mean and standard error in parentheses, all measurements in $\mu \mathrm{m})$.

\begin{tabular}{|c|c|c|c|c|}
\hline Araştırmacı & Bu çalışma & Asmat (2004) & $\begin{array}{l}\text { Martins ve ark., } \\
\quad(2010)\end{array}$ & $\begin{array}{c}\text { Öztürk ve Çam } \\
\text { (2013) }\end{array}$ \\
\hline Konak & $\begin{array}{l}\text { S. fryeri } \\
\text { P. sphenops }\end{array}$ & $\begin{array}{c}\text { Anabas testudineus } \\
\text { Puntius gelinus }\end{array}$ & Ictalurus punctatus & $\begin{array}{c}\text { Neogobius fluviatilis } \\
\text { Proterorbinus } \\
\text { marmoratus } \\
\text { Pomatoschistus } \\
\text { marmoratus }\end{array}$ \\
\hline Yerleşim Yeri & Deri & Solungaçlar & $\begin{array}{l}\text { Deri ve } \\
\text { solungaçlar }\end{array}$ & $\begin{array}{l}\text { Deri solungaç ve } \\
\text { yüzgeçler }\end{array}$ \\
\hline Yer & Antalya, Türkiye & West Bengal, India & $\begin{array}{c}\text { Porto Uniao ve } \\
\text { Santa Catarina, } \\
\text { Brezilya }\end{array}$ & $\begin{array}{l}\text { Kizılırmak Delta, } \\
\text { Samsun, Türkiye }\end{array}$ \\
\hline Vücut çap1 & $50-62(54.72 \pm 0.52)$ & $46.1-61.2(54.6 \pm 3.3)$ & $\begin{array}{c}27.0-77.0 \\
(59.4 \pm 8.5)\end{array}$ & $45-64(51.17 \pm 3.09)$ \\
\hline Yapışkan disk çapı & $34-49(44.85 \pm 0.51)$ & $41.8-52.0(45.6 \pm 2.8)$ & $\begin{array}{c}40.0-72.0 \\
(60.2 \pm 6.7)\end{array}$ & $37-55(43.42 \pm 2.60)$ \\
\hline Dentüküler halka çapı & $23-33(25.4 \pm 0.41)$ & $26.0-33.6(30.4 \pm 1.7)$ & $\begin{array}{c}27.0-47.0 \\
(38.5 \pm 4.5)\end{array}$ & $24-39(27.16 \pm 1.70)$ \\
\hline Merkezi halka çapı & $9-13(11.25 \pm 0.12)$ & $9.2-17.3(13.5 \pm 2.1)$ & - & - \\
\hline Dentükül sayısı & $23-24$ & $21-26(23.1 \pm 1.2)$ & $23-28(24.4 \pm 1.6)$ & $20-26$ \\
\hline Radyal iğne/dentikül & $6-9$ & $9-13(10.8 \pm 1.2)$ & $\begin{array}{c}5.0-15.0 \\
(11.8 \pm 2.1)\end{array}$ & $7-8$ \\
\hline Membran sinır & $2.0-4.0(2.65 \pm 0.10)$ & $3.1-5.6(4.5 \pm 0.6)$ & $3.0-7.0(5.1 \pm 1.7)$ & $4-5(4.75 \pm 0.15)$ \\
\hline Bıçak uzunluğu & $6.0-7.0(6,30 \pm 0,07)$ & $4.0-8.0(6.2 \pm 0.8)$ & $4-6(4.75 \pm 0.22)$ & $4.1-7.1(5.3 \pm 0.6)$ \\
\hline Işın uzunluğu & 6.0 & $5.9-8.2(6.9 \pm 0.7)$ & $\begin{array}{c}3.0-12.0 \\
(8.5 \pm 1.7)\end{array}$ & $5-8(5.58 \pm 0.34)$ \\
\hline Merkezi bölge genişliği & 3.0 & $2.0-3.1(2.8 \pm 0.4)$ & $2.0-6.0(3.8 \pm 0.7)$ & $1-3(2.17 \pm 0.21)$ \\
\hline Dentikül mesafesi & 8.0 & $13.7-17.9(15.0 \pm 1.0)$ & $\begin{array}{c}7.0-13.0 \\
(10.3 \pm 1.2\end{array}$ & $11-17(12.88 \pm 0.65)$ \\
\hline
\end{tabular}




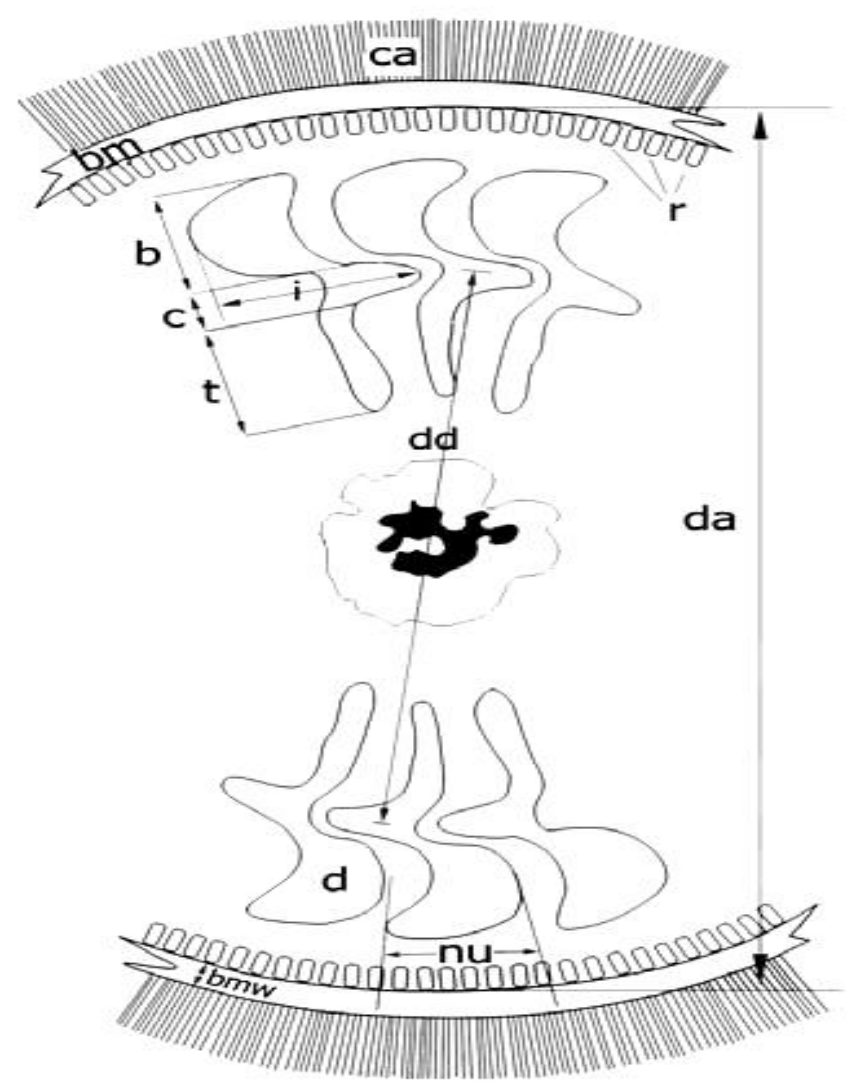

Resim 1. Trichodinid türlerinin tayini için ölçümü yapılan bölgeler: bıçak uzunluğu (b), membran sınırı (bm), membran sınır genişliği (bmw), merkezi bölge eni (c), adoral zon silleri (ca), dentikül (de), yapışkan disk çapı (da), dentikül çapı (dd), dentikül sayısı (dn), dentikül mesafesi (i), radyal iğne sayısı (nu), radyal iğne (r), 1şın uzunluğu (t) (Öğüt ve Altuntaş 2011).

Figure 1. Measuring organelles in trichodinid species; blade lenght (b), border membrane (bm), border membran width (bmw), central part witdh (c), cilia of adoral zone (ca), denticle (de), adhesive disc diameter (da), denticle diameter (dd), denticle number (dn), denticle span (i), radial pin number (nu), radial pin (r), ray lenght (t) (Öğüt and Altuntaş 2011).

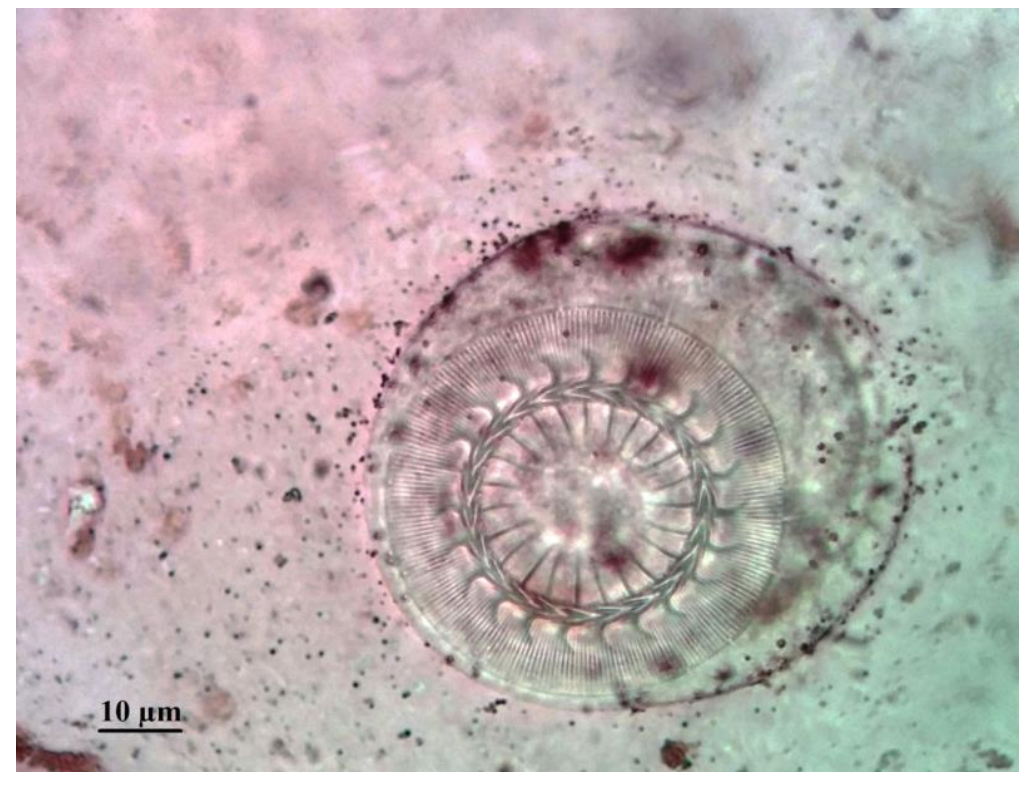

Resim 2. Işı1k mikroskobu altında görüntülenen Trichodina pediculus

Figure 2. Trichodina pediculus under the light microscopy. 


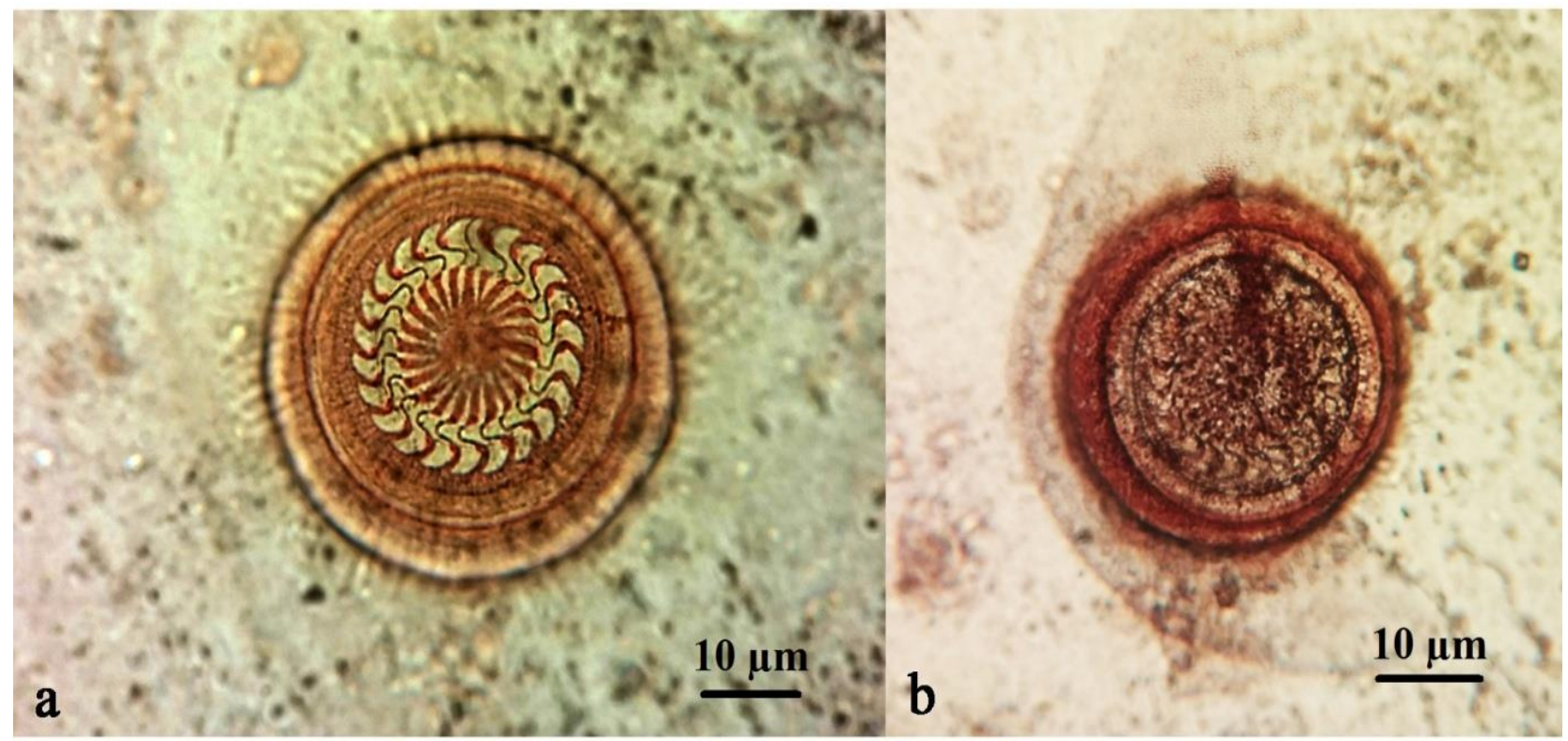

Resim 3 a; S. fryeri den izole edilen ve gümüş-nitrat solüsyonu ile boyanan Trichodina beterodentata nın ventral görüntüsü, b; T. heterodentata nın dorsal görüntüsü.

Figure 3 a; Ventral view of Trichodina beterodentata from $S$. fryeri stained with silver-nitrate solution, b; dorsal view of $T$. heterodentata

\section{TARTIŞMA}

Trichodinidler sucul ekosistemin en s1k görülen parazitlerinden olup konaklarını tatlı su ve deniz balıkları oluşturur. $\mathrm{Bu}$ parazitler akvaryum balıklarında ciddi kayıplara neden olmakla birlikte, akvaryum balikları arasinda beta (Betta splendens), neon tetra (Paracheirodon innesi) ve lepistes (P. reticulata) türlerinin bu parazitlere daha duyarlı olduğu bildirilmiştir (Dobberstein ve Palm 2000, Koyuncu 2009).

Ülkemizde 1998 yllina kadar trichodinid türler hakkında bir rapor mevcut olmayıp, ilk kez 1998 de Trichodina acuta, T. mutablis ve T. nigra trichodinidleri doğal ve kültür balıklarından bildirilmiştir (Özer ve Öztürk 2015). Daha sonra, Öztürk ve Çam (2013) ile Özer ve Öztürk (2015) T. heterodentata'y1 gobi (Neogobius fluviatilis, Proterorbinus marmaratus ve Pomatoschistus marmaratus), dişli sazancik (Aphanius danfordii) ve sudak (Sander lucioperca)'dan tespit etmiştir. Cins seviyesinde ise Trichodina sp. japon (C. auratus), lepistes (P. reticulata), altın moli ( $P$. latipinna), kıllçkuyruk (X. helleri) ve kırmızı plati $(X$. maculatus) balıklarından bildirilmiştir (Koyuncu and Cengizler 2002, Bulguroğlu ve Korun 2013).

Trichodina gibi protozoan parazitler, baliklarda az sayıda bulunduklarında klinik bir bulguya neden olmazlar. Bu nedenle, trichodina enfestasyonlarında tanı sadece mikroskobik gözlem ile yapilır. Parazitle enfeste balıklarda durgunluk, vücut ağırlığında azalma ve solungaçlarda şişkinlik görülür (Durborow 2003). Tang ve Zhao (2007) T. beterodentata ile enfeste japon baliklarınin solungaçlarında epitelyal dökülme, yangı ve yapısal bozukluk bildirirken, Vallado ve ark., (2015) ise bu trichidinid türün tespit edildiği balıklarda ciddi proliferatif lezyonları bildirmiştir. Mevcut çalışmada, 600 balık örneğinin 82'sinin trichodinid türler ile enfeste olduğu bulunmuştur. Bu türlerin 42'si Trichodina pediculus, 40' 1 ise $T$. beterodentata olarak tanımlanmıştır. Çalışmada T. pediculus ve $T$. heterodentata ile enfeste baliklarda, parazit sayısının düşük olması nedeniyle Durborow (2003), Tang ve Zhao (2007) ve Vallado ve ark., (2015) tarafindan bildirildiği gibi durgunluk, vücut ağırlığında azalma ve solungaç filamentlerinde hasar nedeni ile solungaç doku yapısında değişiklik ve bozukluk tespit edilmemiştir.

Trichodinid türlerinin çoğu balıkların solungaçlarında bulunurken, az bir kısmı ise balıkların sadece vücut yüzeyinde bulunur. $T$. pediculus ve $T$. acuta türlerinin enfeste balikların derisinde gözlenmesine karşın solungaçlarda bildirilmemiştir. Bununla birlikte, T. heterodentata gibi sık rastlanılan türlerin ise balıkların solungaç ve derilerinde görüldüğü rapor edilmiştir (Basson ve Van As 2006, Abowei ve ark., 2011). Çalışmada enfeste sar1 prenses, mavi prenses, velifera, beyaz moli ve ahli çiklit balıklarının derisinden hazırlanan sürtme preparatlarda $T$. pediculus ve $T$. heterodentata türleri tespit edilirken, solungaçlardan hazırlanan preparatlarda ise $T$. beterodentata tespit edilmemiştir. T. pediculus ün ayırt edici karakteristik özelliği dentikül sırasıdır. Bu sıralar uzun ve gittikçe sivrilen yapıdadır. Yapışkan diskin merkezinde, merkezi kısım belirgin olmaksızın granüler görünür (Gaze ve Wootten 1998). Bashe ve Abdullah (2010) Irak' ta Mastacembelus mastacembelus' un derisinden $T$. pediculus'u izole etmiştir. Araştırmacilar, parazitin vücüt çapını 55-70 $\mu \mathrm{m}$, yapişkan disk çapını 43-66 $\mu \mathrm{m}$, dentiküler halka çapını 28.3-46.6 $\mu \mathrm{m}$, dentikül 
sayısını 25-30, 1şın uzunluğunu 9-9.6 $\mu \mathrm{m}$, biçak uzunluğunu 5-6 $\mu \mathrm{m}$ olarak bildirmiştir. Bu ölçümler çalışmamızdaki T. pediculus ölçümleri ile benzerlik gösterdiği anlaşılmıştır. Valladao ve ark., (2014), Prochilodus lineatus larvasinın ağı, solungaç, yüzgeçler ve vücut yüzeyinden $T$. heterodentata'y1 izole etmiştir. Araştırıcılar, parazitin vücut çapını

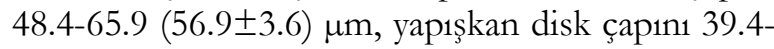
$55.3(47.7 \pm 3.6) \mu \mathrm{m}$, dentiküler halka çapını 23.0$37.6(29.4 \pm 2.6) \mu \mathrm{m}$, dentikül sayisinı 20-26, membrane sinır genişliğini $2.8-5.7(4.5 \pm 0.4) \mu \mathrm{m}$, dentikül uzunluğunu 5.8-9.3 (7.8 \pm 0.7$) \mu \mathrm{m}$, biçak

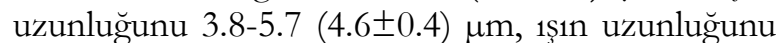
6-9.9 (7.7 \pm 0.8$) \mu \mathrm{m}$, dentikül mesafesini 13.0-17.6

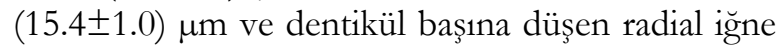
sayısını 6-12 olarak belirlemiştir. Bu ölçümler, çalışmamızda elde edilen ölçümler ile benzerlik gösterdiği bulunmuştur.

Piazza ve ark., (2006) Brezilya’ da akvaryum balığ1 türlerinin parazitik faunasını araştırmışlardır. Araştırmacılar japon, plati, kılıçkuyruk ve moli dahil 189 balığ1 incelemiştir. Çalışma sonuçlarına göre incelenen balikların T. acuta ile enfeste olduklar1 ve bu trichodinid parazitin prevalansının \%4.7 olduğu tespit edilmiştir. Çalışmamızda Trichodina türlerinin prevalans1 600 balıkta \% 14.9 olarak bulunmuştur. En s1k görülen trichodinid türü T. pediculus (11.6\%) olup, T. heterodentata' nin baskinlığ1 \% 3.3 olmuştur. Durborow' un (2003) bildirdiği gibi çalışmada enfeste balıklarda parazit sayısının düşük olması nedeniyle, bu balıklarda ciddi kayılara neden olmadı̆̆ı anlaşılmıştır.

Çoğu trikodinid tür, çok az konak spesifikliği sergilerken diğerleri konağa spesifiktir. Konağa spesifik trichodinidler, sadece bir kaç istisnai durumda solungaç parazitidir. $T$. centrostrigata, Cichlidae familyası ile ilişkilidir. Japon balıklarında T. reticulate bildirilirken, T. kazubski Güney Afrika' da Barbus spp.' de bulunmuştur, $T$. nobilis ve $T$. kupermani ise asya sazanında tespit edilmiştir (Basson ve Van As 2006, Abowei ve ark., 2011).

T. heterodentata çiklit türlerini tercih eden tür olarak tanımlanır ancak parazit farklı balık türlerini de etkileyebilir. Şu ana kadar, dünya genelinde 50'den fazla balık türünde tanımlanmıştır. En çok etkilenen balık türleri çiklitler ve cyprinidler olmasina rağmen, Eleotridae ve Poecilidae familyalarına dahil olan balıkların çoğunun bu türle enfeste olduğu bildirilmiştir (Miranda ve ark., 2012). Çalışmamızda, T. heterodentata' nın ahli çiklit (S. fryeri) ve beyaz moli (P. sphenops)' yi enfeste ettiği tespit edilmiştir. Miranda ve ark., (2012), diğer araştırmacıların bu parazitin konak balık tercihinin olmadığ1 hipotezine dikkat çekerek, bu soruyu cevaplamak için daha fazla sayıda familyaya ait balıklarla yapılmış çalışmaya ihtiyaç duyulduğunu öne sürmüştür. Bununla birlikte, mavi prenses ve beyaz moli türleri, Cichlidae ve Poecilidae familyalarının üyeleri olup, $T$. heterodentata' nin konak tercihi üzerine verilen yukarıdaki bilgiler, bu çalışmanın verileriyle uyumlu olduğu anlaşılmaktadır.

\section{SONUÇ}

Trichodinid parazitler balıkta düşük sayıda bulunduklarında klinik bir bulguya yol açmayabilir. Sonuç olarak, çalışmamızda incelenen balık türlerinde trichodinid parazitlerin klinik bir bulguya neden olmadığ1 tespit edilmiştir. Trichodina beterodentata ülkemizde ilk kez aşağı Kızılırmak Delta'sında mevcut balık türlerinden bildirilirken (Özer ve Öztürk 2015), çalışmamızda ise akvaryum balığ1 türlerinde tespit edilmiştir. T. pediculus ise Çapar Dinçer (2016) tarafindan Mogan Gölü'nde tespit edilirken, çalışmamızda ise ciklit ve molilerden izole edilmiştir. Bu türün konak seçiciliğinin az, ancak konak dağılımının Cyprinidae, Cichlidae, Centrarchidae, Odontobutidae ve Nonidae familyaları ile sinırlı olduğunun rapor edilmesine (Drobinia ve ark., 2014) karşın, çalışmamızda Poecilidae familyasına ait moliden tespit edilmiştir.

\section{KAYNAKLAR}

Abowei JFN, Briyai OF, Bassey SE. A review of some basic parasite diseases in culture fisheries flagellids, dinoflagellides and ichthyophthriasis, ichtyobodiasis, coccidiosis trichodiniasis, helminthiasis, hirudinea infestation, crustacean parasite and ciliates, Br J Pharmacol Toxicol. 2011; 2(5): 213-226.

Asmat GSM. First record of Trichodina diaptomi (Dogiel, 1940) Basson and Van As, 1991, T. heterodentata Duncan, 1977 and T. oligocotti (Lom, 1970) (Ciliophora: Trichodinidae) from Indian fishes. Paki J Bio Sci. 2004; 7(12): 2066-2071.

Athanassopoulou F, Pappas IS, Bitchava K. An overview of the treatments for parasitic disease in Mediterranean aquaculture, Ciheam, Options Méditerranéennes. 2009; 86: 65-83.

Bulguroğlu SY, Korun J. Ectoparasitic infestations on cultured gold fish (Carassius auratus) in the Antalya Region and their treatment (abstract only). In: XVII. National Fisheries Symposium; 3-6 September 2013; İstanbul, Turkey (in Turkish)

Bashe SKR, Abdullah SMA. Parasitic fauna of spiny eel Mastacembelus from Greater Zab river in Iraq. Iran J Vet Res. 2010; 11(1):1827. 
Basson L, Van As J. Trichodinidae and Other Ciliophorans (Phylum Ciliophora). Ed. by K. T. Woo, In: Fish Diseases and Disorders, Volume 1: Protozoan and Metazoan Infections, CAB International, Canada, 775 pages, 2006; pp. 154-182.

Çapar Dinçer S. Freshwater ciliates from Beytepe pond in Ankara with new records for Turkey. Turk J Zool. 2016; 40:1-12.

Dobberstein RC, Palm HW. Trichodinid ciliates (Peritrichia: Trichodinidae) from the Bay of Kiel, with description of Trichodina claviformis sp. n. Fol Parasitol. 2000; 47:8190 .

Dove ADM. Richness patterns in the parasite communities of exotic poeciliid fishes. Parasitol. 2000; 120:609-62.

Dove AD, O'donoghue PJ. Trichodinids (Ciliophora: Trichodina) from native and exotic australian freshwater fishes. Acta Parasitol. 2005; 44:51-60.

Duncan BL. A study on trichodinids from freshwater fishes in Chongqing II. J. Chongqing Norm Univ Nat Sci Ed. 1977; 4:8-15.

Durborow RM. Protozoan Parasites. SRAC Publication, No: 4701. 2003; Pp 8.

Gaze WH, Wootten R. Ectoparasitic species of the genus Trichodina (Ciliophora: Peritrichida) parasiting British freshwater fish. Folia Parasitol. 1998; 45:177-190.

Ghosh A, Mahapatra BKD, Atta NC. Ornamental fish farming-successful small scale aqua business in India. Aquaculture. 2003; 11(3):14-16.

Iqbal Z, Hassain V. Parasitic infection of an ornamental fish, shubunkin Carassius auratus L. imported to Pakistan. Biologia. 2013; 59(29):281-286.

Iqbal Z, Haroon F. Parasitic infections of some freshwater ornamental fishes imported in Pakistan. Pakistan J Zool. 2014; 46(3):651656.

Kazubski SL. Morphological variation of the ciliate Trichodina pediculus Ehrenberg, 1838. III. Parasitising on crucian carp (Carassius carassius (L.) from small ponds in Kortowo (Olsztyn). Acta Protozool. 1991; 30:187-192.

Klein BM. The 'dry' silver method and its proper uses. J. Protozool. 1958; 5:99-103.

Koyuncu CE, Cengizler $\dot{\text { I. Protozoan }}$ ektoparasites occuring in some of the aquarium fishes (Poecilidae) raised in Mersin District. EgeJFAS. 2002; 19(3-4):293-301.

Koyuncu CE. Parasites of ornamental fish in Turkey. Bull Eur Ass Fish Pathol. 2009; 29(1):25-27.

Ling KH, Lim LY. The status of ornamental fish industry in Singapore, Singapore J Prim Indust. 2005; 32:59-69.

Lom J, Dykovà L. Protozoan Parasites of Fishes. Developments in Aquaculture and Fisheries Science. 26. Elsevier Science Publishers B.V. Amsterdam, 1992; pp. 315

Mandal B, Dutta C, Laha UK. Freshwater ornamental fish farming as a tool for socioeconomic development of backward women self-help groups (SltG's) to restore livelihood security. International Journal of Applied and Basic Medical Research. 2012; 2(1):95-98.

Martins, ML, Marchiori N, Nunes G, Rodrigues MP. First record of Trichodina heterodentata (Ciliophora: Trichodinidae) from channel catfish, Ictalurus punctatus cultivated in Brasil. Brazilian J Biol. 2010; 70(3):637-644

Martins M.L., Marchiori N, Roumbedakis K, Lami F. Trichodina nobilis Chen, 1963 and Trichodina reticulata Hirschmann et Partsch, 1955 from ornamental freshwater fishes in Brazil. Brazilian J. Biol. 2012; 72(2):281-286

Miranda LH, Marchiori N, Alfaro CR, Martins ML. First record of Trichodina heterodentata (Ciliophora: Trichodinidae) from Arapaima gigas cultived in Peru. Acta Amazon. 2012; 42(3):433-438.

Öğüt H, Altuntaş C. Monthly variation in the morphological characteristics of Trichodina sp. (Ciliophora: Peritrichida) found on whiting Merlangius merlangus euxinus. RBMO. 2011; 46(2):269-274

Özer A, Öztürk T. Trichodinid fauna of freshawater fishes with infestation indices in the Lower Kizilirmak Delta in Turkey and a checklist of trichodinids (Ciliophora: Trichodinidae) in Turkish waters. Turk J Zool. 2015; 39:749-761.

Öztürk T, Çam A. Trichodinid parasites (Protozoa: Ciliophora: Peritrichida) of invasive Gobiid fish inhabiting the lower Kizılırmak delta in Samsun, Turkey. Pakistan J Zool. 2013; 45(6):1517-1524.

Piazza RS, Martins ML, Guiraldelli L, Yamashita MM. Parasitic diseases of freshwater ornamental fishes 
commercialized in Florianópolis, Santa Catarina, Brazil. B Inst Pesca São Paulo. 2006; 32(1):51-57.

Roberts RJ. Fish Pathology, Institute of Aquaculture, University of Stirling, Scotland 1989

Singh ISB, Sreedharan K. Ornamental fish disease and their management Tang FH, Zhao YJ. (2007) Taxonomic study on three species of Trichodina Ehrenberg, 1838 with pathologic research on gill tissue of Carassius auratus caused by Trichodina heterodentata measures. CMFRI. 2009;16(03): 244-253.

Thilakaratne I, Rajapaksha G, Hewakopara A, Rajapakse RPVJ, Faizal ACM. Parasitic infections in freshwater ornamental fish in Sri Lanka, DAO. 2003; 54:157-162.

Valladao GMR, Gallani SU, De padua SB, Martins ML, Pilarski F. Trichodina heterodentata (Ciliophora) infestation on Prochilodus lineatus larvae: a host-parasite relationship study. Parasitol. 2014;141(5): 662-669.

Velasco-Santamaría Y, Corredor- Santamaría W. Nutritional requirements of freshwater ornamental fis: a review. Rev MVZ Cordoba. 2011; 16(2), 2458-2469. 